\title{
Characterization of the lipid profile post mortem for Type- 2 diabetes in human brain and plasma of the elderly with LCMS-techniques: a descriptive approach of diabetic encephalopathy
}

\author{
V van Ginneken*1, E Verheij ${ }^{2}$, M Hekman ${ }^{2}$ and J van der Greef ${ }^{2,3}$ \\ ${ }^{1}$ Blue Green Technologies, Runderweg 6, 8219 PK, Lelystad, Netherlands \\ ${ }^{2}$ TNO Pharma, Analytical Systems Biology, P.O.Box 360, 3700 AJ Zeist, The Netherlands \\ ${ }^{3}$ Sino-Dutch Center for Preventive and Personalized Medicine, Leiden University, P.O.Box 950, 22300 RA Leiden, The Netherlands
}

\begin{abstract}
Objectives: This study was designed to give more insight in the lipid profile of brain and blood plasma for post mortem type 2 diabetic (T2DM) elderly patients in comparison to a Control group $(\mathrm{Co})$ to give a descriptive approach of diabetic encephalopathy.

Methods: Reversed phase liquid chromatography coupled to mass spectrometry (LC-MS) was used to quantify and qualify the rearrangement and repartitioning of fat stores in the brain of male post mortem subjects (Co $n=8 ; 73.5 \pm 10.5$ years; T2DM, n=8; $77.3 \pm 7.2$ years) which were obtained from the 'Netherlands Brain Bank'. Differences were calculated by a Principal Component Analysis (PCA).

Results: We observed that the saturation index of the Cholesterylester for 16:0 was significantly higher in white matter of T2DM patients in comparison to white matter of the control group $(\mathrm{P} \leq 0.05)$ which was earlier observed in schizophrenic postmortem brain subjects [1]. Furthermore we can conclude there are no significant difference between summarized relative concentrations of the different lipid compounds in human brain homogenate (white vs. grey) of two patients groups: one Control-group ( $\mathrm{N}=8)$ and one Diabetes-2 (T2DM) group (N=8). For three Monoglycerides the values were significantly higher in the T2DM group. For 18:2 MG

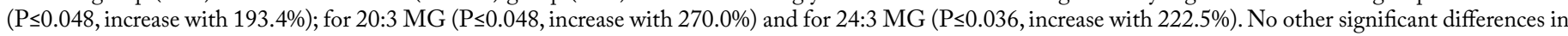
brain lipid composition were observed between the control and T2DM group. In T2DM patients plasma lipid profiles (109 components) were more scattered. Few differences in plasma fat composition (triacylglycerols, free fatty acids (NEFA), cholesterol, (HDL)-cholesterol) were observed between the Co and T2DM group. Plasma fructosamine was significantly higher in T2DM patients which was a reliable indicator for type 2 diabetes.
\end{abstract}

Conclusion: Diabetic encephalopathy which often occurs in T2DM patients can probably more described to microvasculair complications and/or changes in the saturation degree of the several lipid compounds especially for C16:0. Saturation degree issues will be worked out in another manuscript. Our major conclusion is that diabetic encephalopathy in T2DM patients is not the result of an aberrant lipid metabolism.

\section{Introduction}

For the elderly, world-wide there is an increase in life expectancy. New indicators of ageing were used by [2] and all their measures indicate a continuous ageing of the world's population throughout the century. The median age of the world's population increases from 26.6 years in 2000 to 37.3 years in 2050 and then to 45.6 years in 2100 . Because the prevalence of type 2 diabetes T2DM increases with age [3], partly due to sarcopenic obesity [4] and a more sedentary lifestyle [5]. The prevalence of diabetes (type 2 diabetes and type 1 diabetes) will increase by $54 \%$ to more than 54.9 million Americans between 2015 and 2030; annual deaths attributed to diabetes will climb by $38 \%$ to 385,800 ; and total annual medical and societal costs related to diabetes will increase 53\% to more than $\$ 622$ billion by 2030 [6]. Macrovascular disease, such as cardiovascular diseases, peripheral diabetic neuropathy (DN) [7], and stroke are common complications of the pathogenesis of T2DM [8] and the leading cause of death among people with T2DM [9].

But also IR/T2DM can affect the function of the brain and result in mental deterioration as a result of physical changes in the brain. It may be due to degenerative change, circulatory disease, senile dementia which results in a progressive loss of mental faculties such as memory and orientation, by lowered performance on several cognitive domains, depression and Alzheimer disease [10].

Some of the "brain-diseases" as a consequence of T2DM are associated with the occurrence of well-described microvascular complications and can be associated with slowly progressive brain damage often referred as "diabetic encephalopathy" and are characterized by mild to moderate impairments in cognitive functioning [11]. The magnitude of these cognitive deficits appears

Correspondence to: V van Ginneken, Blue Green Technologies, Runderweg 6, 8219 PK, Lelystad, Netherlands, E-mail: vvanginneken@hotmail.com

Key words: human brain, diabetes type-2, diabetic encephalopathy, lipid compounds, blood plasma

Received: March 18, 2017; Accepted: April 07, 2017; Published: April 10, 2017 
mild to moderate, but can significantly hamper daily functioning in processes as attention and executive functioning, information processing, speed and memory, in this way adversely affecting quality of life [12].

A worse scenario is that these "brain-diseases" as a consequence of IR/T2DM are also associated with an increased risk of dementia [13] and depression [14-16]. Patients with T2DM also show changes on brain MRI, such as cortical and hippocampal atrophy and changed blood brain barrier permeability $[17,18]$.

These "brain-diseases" as a consequence of IR/T2DM have also an impact on our medical system and e.g. the healthcare costs for people with T2DM and coexisting depression are estimated approximately 2.5 times higher: (USD3,3264) in comparison to patients with T2DM alone (USD 1,297) [19].

Therefore, not only considering "the quality of life" but also from economical considerations it is important to elucidate the mechanisms behind "brain-diseases", further in this manuscript called with the term "diabetic encephalopathy" as a consequence of IR/T2DM pathogenesis.

Membrane phospholipid fatty acids are derived from dietary fatty acids as well as de novo synthesis [20]. With regard to dietary fatty acids, alterations in the proportion of poly-unsaturates to saturates have been shown to affect membrane phospholipid fatty acids and could have contributed to the fatty acid composition and IR in general. Increasing the content of polyunsaturated fatty acids within cell membranes would increase the membrane fluidity, the number of insulin receptors and the action of insulin for muscle tissue. A converse effect occurs when the concentration of saturated fatty acids in the membranes is increased $[21,22]$. But also for brain tissue it can be expected that lipids play a key role in determining membrane fluidity, saturation degree and changes in lipid and fatty acids composition have been reported to alter important cellular functions [1,22,23]. However it is not known whether diabetic encephalopathy develops as a result of aberrant lipid metabolism [24]. Membrane phospholipid abnormalities have been observed in brain tissue of schizophrenic patients when compared to a control group [1]. Studies on brain tissue of diabetic patients have so far not been reported.

We hypothesize that there are structural changes in lipid brain composition of a T2DM patient group which can explain all earlier mentioned characteristics of diabetic encephalopathy $[25,26]$. In order to test whether the blood-brain barrier was changed we also determined leptin and insulin in plasma and brain homogenate of the two groups. In addition we measured elongation activity based on the 16:0-to-18:0 ratio. Decreased 16:0-to-18:0 ratio (decreased elongation) was associated with decreased insulin sensitivity in a cross-sectional study with humans [20]. The major aim of this study is to compare the biochemical lipid composition in brain and blood between T2DM patients with controls. With LC-MS techniques we measured cholesterylesters (ChE), lysophosphatidylcholines (LPC), phosphatidylcholine (PC), sphingomyelin (SPM), diacylglycerols (DG) and triacylglycerols (TG) in the cortex and blood plasma.

\section{Material and methods}

\section{Brain-tissue}

Human Brain tissue was obtained from the "Netherlands Brain Bank". Causes of death causes are presented in Table 1. Of the 16 patients apolipoprotein E genotype was assessed in 15, the Alzheimer risk allele ApoE 4 was present in one control patient and one T2DM patient.

Time of post mortem dissection varied between 4.4 and 24.5 hours (Table 1). The region of post mortem collection of the tissue material was mainly the cortex (Table 1).

Table 1. Autopsy report of eight Control subjects and eight Diabetes-2 subjects including sex, age, diagnosis, 'Braak'-stage ('BS') ([27]Braak et al. 1993 ), pH-csf: pH of liquor post mortem dissection (PM-dis.), brain-weight (BW), ApoE genotype alleles, and cause of death. Material derived from "the Netherlands Brain bank".

\begin{tabular}{|c|c|c|c|c|c|c|c|c|c|c|c|}
\hline No. & Autop-sy & Sex & Age & Region & Diagnosis & 'BS' & pH-csf & BW & ApoE & $\begin{array}{l}\text { Time PM } \\
\text { Dis. (h) }\end{array}$ & Cause of death \\
\hline Co-1 & $00 / 097$ & M & 78 & Superior parietal gyrus & Non-demented & 1 & 6.42 & 1332 & 33 & 6.55 & Cardiac failure, sudden death \\
\hline $\mathrm{Co}-2$ & $01 / 054$ & M & 77 & Cingulated gyrus & Non-demented & 1 & 7.19 & 1138 & 32 & 8.25 & $\begin{array}{l}\text { Perforation of the bladder wall } \\
\text { during a transurethral resection of } \\
\text { the bladder }\end{array}$ \\
\hline $\mathrm{Co}-3$ & $01 / 055$ & M & 79 & Superior parietal gyrus & Non-demented & 1 & 6.02 & 1334 & 43 & 7.40 & Bronchopneumonia and sepsis \\
\hline $\mathrm{Co}-4$ & $01 / 115$ & M & 83 & Cingulated gyrus & Non-demented & 1 & 6.49 & 1422 & 33 & 4.35 & Heart attack \\
\hline Co-5 & 03/009 & M & 51 & Cingulated gyrus & Non-demented & 1 & 6.2 & 1190 & 33 & 7.44 & Ventricle fibrillation \\
\hline Co-6 & $06 / 117$ & M & 66 & Cingulated gyrus & Non-demented & 0 & 6.7 & 1590 & - & 7.45 & Ruptured abdominal aneurysm aorta \\
\hline $\mathrm{Co}-7$ & $98 / 326$ & M & 81 & Medial temporalis gyrus & Non-demented & 3 & 6.64 & 1276 & 33 & 5.20 & Unspecified respiratory problems \\
\hline $\mathrm{Co}-8$ & $00 / 142$ & M & 73 & Superior parietal gyrus & Non-demented & 0 & - & 1267 & 33 & 24.45 & Not given \\
\hline Mean \pm SD & & & $\begin{array}{l}73.5 \\
\pm \\
10.5\end{array}$ & & & & $6.52 \pm 0.38$ & $\begin{array}{l}1319 \pm \\
140\end{array}$ & & $\begin{array}{l}8.89 \\
\pm \\
6.42\end{array}$ & \\
\hline DM-1 & $01 / 194$ & M & 88 & Cingulated gyrus & Non-demented & 1 & 6.84 & 1398 & 32 & 7.00 & Heart failure \\
\hline T2DM & $02 / 081$ & M & 79 & Cingulated gyrus & $\begin{array}{l}\text { Contr. With Non-Hodgkin } \\
\text { lymphomona }\end{array}$ & 1 & 6.53 & 1382 & 43 & 6.15 & $\begin{array}{l}\text { Acute dyspnea and dehydration, } \\
\text { perhaps as a result of colon carcinoma }\end{array}$ \\
\hline DM-3 & $02 / 258$ & M & 71 & Cingulated gyrus & Non-demented & 1 & 6.2 & 1190 & 33 & 7.40 & Sepsis \\
\hline DM-4 & $04 / 024$ & M & 82 & Inferior temporalis gyrus & Multiple sclerosis & 1 & 6.42 & 1391 & 33 & 5.35 & Pneumonia \\
\hline DM-5 & $04 / 233$ & M & 70 & Cingulated gyrus & Vascular dementia & 1 & 6.15 & 1110 & 33 & 10.15 & $\begin{array}{l}\text { Respiratory failure caused by lung } \\
\text { embolus or aspiration pneumonia }\end{array}$ \\
\hline DM-6 & $05 / 298$ & M & 73 & Cingulated gyrus & Parkinson disease & 1 & 6.28 & 1572 & - & 6.35 & Aspiration pneumonia \\
\hline DM-7 & $98 / 280$ & M & 85 & Medial frontal gyrus & Non-demented & 2 & 6.23 & 1394 & 32 & 5.13 & Cardiac tamponade \\
\hline DM-8 & $00 / 256$ & M & 70 & Cingulated gyrus & Park.dis. with dementia & 1 & 6.33 & 1258 & 33 & 9.05 & Pneumonia, septic shock (erysipelas) \\
\hline Mean \pm SD & & & $77.3 \pm 7.2$ & & & & $6.37 \pm 0.22$ & $1337 \pm 145$ & & $7.07 \pm 1.76$ & \\
\hline T-test & & & $\mathrm{P} \leq 0.42$ & & & & & & & & \\
\hline
\end{tabular}


Visually, a clear separation could be made between grey and white matter in the cortex. A tissue homogenate of the brain tissue (grey or white; $10 \%$ wet weight/ volume) in phosphate-buffered saline (PBS) was made with the Mini-beat Beater.

For Alzheimer stage 1 there is no accumulation of abnormally phosphorylated tau protein. For stage 5 abnormally accumulation of this protein can be observed, a hallmark of Alzheimer disease [27]. All patients were in stages varying between $0-2$ with exception of patient Co-7 which was at stage 3 .

\section{Blood plasma}

Blood was centrifuged at $8000 \times \mathrm{x}$ for $5 \mathrm{~min}$. The plasma was aliquoted and stored at $-80^{\circ} \mathrm{C}$ at the "Netherlands Brain Bank" pending analysis

\section{Measurement of blood parameters}

Alanine aminotransferase (ALT), aspartate aminotransferase (AST), triglycerides, non-esterified fatty acids (NEFA), cholesterol, (HDL)-cholesterol, glucose and fructosamine were measured on a Roche Modular P800 chemistry analyzer using Roche reagents (Roche Diagnostics, Mannheim, Germany) or reagent of WAKO Chemicals, Japan, for NEFA.

\section{Measurement of insulin and leptin}

Insulin was measured using an ImmunoRadioMetric Assay of Biosource Europe (Nivelles, Belgium). Leptin was measured using a Radioimmunoassay of Linco Research (St Charles, MI, USA, part of Millipore Company).

\section{LC-MS of lipids and fatty acids in blood plasma}

Lipids and free fatty acids (FFA) were analyzed with electrospray LCMS as earlier performed [28-32]. Samples, $10 \mu$ plasma, were extracted with $300 \mu \mathrm{l}$ of isopropanol (IPA) containing several internal standards (IS: C17:0 lysophosphatidylcholine, di-C12:0 phosphatidylcholine, tri-C17:0 glycerol ester, C17:0 cholesterol ester and heptadecanoic acid (C17:0)). After mixing and centrifugation the supernatant was transferred to an autosampler vial. Lipids were separated on a $150 \mathrm{x}$ $3.2 \mathrm{~mm}$ i.d. C4 Prosphere column (Alltech, USA) using a methanol gradient in $5 \mathrm{mM}$ ammonium acetate and $0.1 \%$ formic acid (mobile phase A: $5 \%$ methanol, mobile phase B: $90 \%$ methanol). The flowrate was $0.4 \mathrm{ml} / \mathrm{min}$ and the gradient was as follows: $0-2 \mathrm{~min}-20 \% \mathrm{~B}, 2-3$ min $-20 \%$ to $80 \% \mathrm{~B}, 3-15 \mathrm{~min}-80 \%$ to $100 \% \mathrm{~B}, 15-25 \mathrm{~min}-$ hold $100 \% \mathrm{~B}, 25-32 \mathrm{~min}$-condition at $20 \% \mathrm{~B}$.

The instrument used was a Thermo LTQ equipped with a Thermo Surveyor HPLC pump. Data were acquired by scanning the instrument from $\mathrm{m} / \mathrm{z} 300$ to 1200 at a scan rate of approximately 2 scans/s in positive ion ESI mode.

The FFA LC-MS platform employs the same sample and similar HPLC conditions as the lipid method. The ammonium acetate concentration is $2 \mathrm{mM}$ instead of $5 \mathrm{mM}$ and no formic acid was added. The gradient: $0-2 \mathrm{~min}-30 \% \mathrm{~B}, 2-3 \mathrm{~min}-30 \%$ to $70 \% \mathrm{~B}, 3-10 \mathrm{~min}-70 \%$ to $100 \% \mathrm{~B}, 10-15 \mathrm{~min}-$ hold $100 \% \mathrm{~B}, 15-20 \mathrm{~min}-$ condition at $30 \% \mathrm{~B}$. Detection of FFA is performed in negative ion ESI mode. Combined the two methods provide (semi)quantitative data for approximately 200 different identified lipids and FFA.

Each extract was injected three times $(10 \mu \mathrm{l})$, once for the LC-MS FFA platform and two times for the LC-MS lipid platform. Furthermore, a quality control (QC) sample was prepared by pooling the samples.
The pool was divided into $10 \mu$ aliquots that were extracted the same as the study samples. The QC samples were placed at regular intervals in the analysis sequence (one QC after every 10 samples). The QC samples served two purposes. The first is a regular quality control sample to monitor the LC-MS response in time. After the response has been characterized, the QC samples were used as standards of unknown composition to calibrate the data.

In plasma samples, the 6 dominant lipid classes observed with these two methods are the lyso-phosphatidylcholines (IS used: C17:0 lyso-phosphatidylcholine), phosphatidylcholines (IS used: di-C12:0 phosphatidylcholine), sphingomyelines (IS used: di-C12:0 phosphatidylcholine), cholesterylesters (IS used: C17:0 cholesterylester), triacylglycerols (IS used: tri-C17:0 glycerol ester), and free fatty acids (IS used: C17:0 FFA) (Figure 1A \& B, Annex 1). In addition to these lipids, the extracts also contain minor lipids, but these were either not detected (concentration too low relative to very abundant lipids like phosphatidylcholines and diacylglycerols, DG) or they were not included in data processing with exception of the DG. The LC-MS lipid

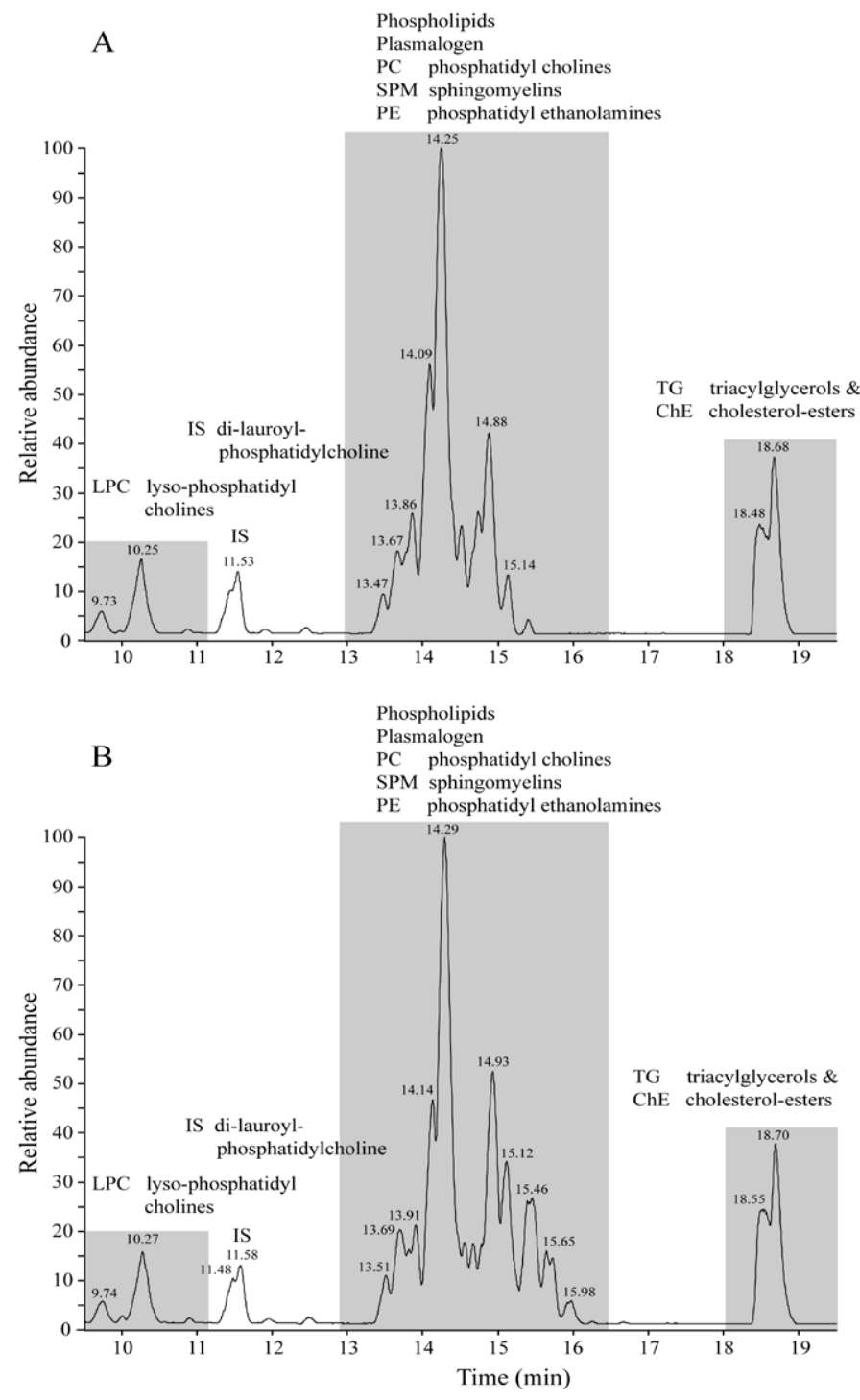

Figure 1. Using reversed phase liquid chromatography coupled to mass-spectrometry (LC MS) a chromatogram was obtained of the brain-homogenate of a Co-patient no.1 (Figure 1A) and a type-2 (T2DM) patient. 
and LC-MS FFA data were processed using the LC-Quan software (Thermo).

\section{Mass spectrometry brain tissue}

Fifty $\mu \mathrm{L}$ of the brain homogenate was mixed with $1000 \mu \mathrm{L}$ IPA containing 4 internal standards. Samples were placed in an ultrasonic bath for 5 minutes. Thereafter, samples were centrifuged at 10,000 rpm for 3 minutes followed by injection of $10 \mu \mathrm{L}$ on the LC-MS Instrument (Thermo Electron, San Jose, USA). A Thermo LTQ is a linear iontrap LC-MS instrument (Thermo Electron, San Jose, USA). Internal standard C24:0 PC was used to correct the data for small variations in analysis, such as sensitivity and injection volume.

In brain homogenate, the 8 dominant lipid classes observed with these two methods are the lyso-phosphatidylcholines (IS used: C17:0 lyso-phosphatidylcholine), plasmalogens, phosphatidylcholines (IS used: di-C12:0 phosphatidylcholine), sphingomyelines (IS used: diC12:0 phosphatidylcholine), ethanolamines, cholesterylesters (IS used: C17:0 cholesteryl ester), triacylglycerols (IS used: tri-C17:0 glycerol ester), and free fatty acids (IS used: C17:0 FFA) (Figure 1A \& B \& Figure 3A \& B, Annex 1,2).

\section{Analysis of plasmalogens}

Analysis of cholesterylesters (ChE), lysophosphatidyl-cholines (LPC), phosphatidylcholine (PC), sphingomyelin (SPM) and triacylglycerols (TG) were based on molecular mass and retention time using internal standards. Because no standards for the plasmalogens exist, mass lists determined by using atmospheric pressure chemical ionization (APCI) and electrospray ionization (ESI) mass spectrometry (MS) techniques were used [33]. These mass lists were published on internet www.byrdwell.com/plasmogens and www.byrdwell.com/PhosphatidylEthanolamine.

\begin{tabular}{|l|l|l|l|l|l|l|l|l|l|}
\hline Co & & Co & & Autopsy & T2DM & & T2DM & & Autopsy \\
\hline $\mathbf{1}$ & G & $\mathbf{9}$ & W & S00_097 & $\mathbf{1 7}$ & G & $\mathbf{2 5}$ & W & S00_256 \\
\hline $\mathbf{2}$ & G & $\mathbf{1 0}$ & W & S00_142 & $\mathbf{1 8}$ & G & $\mathbf{2 6}$ & W & S01_194 \\
\hline $\mathbf{3}$ & G & $\mathbf{1 1}$ & W & S01_054 & $\mathbf{1 9}$ & G & $\mathbf{2 7}$ & W & S02_081 \\
\hline $\mathbf{4}$ & G & $\mathbf{1 2}$ & W & S01_055 & $\mathbf{2 0}$ & G & $\mathbf{2 8}$ & W & S02_258 \\
\hline $\mathbf{5}$ & G & $\mathbf{1 3}$ & W & S01_115 & $\mathbf{2 1}$ & G & $\mathbf{2 9}$ & W & S04_024 \\
\hline $\mathbf{6}$ & G & $\mathbf{1 4}$ & W & S03_009 & $\mathbf{2 2}$ & G & $\mathbf{3 0}$ & W & S04_233 \\
\hline 7 & G & $\mathbf{1 5}$ & W & S06_ 117 & $\mathbf{2 3}$ & G & $\mathbf{3 1}$ & W & S05_298 \\
\hline $\mathbf{8}$ & G & $\mathbf{1 6}$ & W & S98_326 & $\mathbf{2 4}$ & G & $\mathbf{3 2}$ & W & S98_280 \\
\hline
\end{tabular}

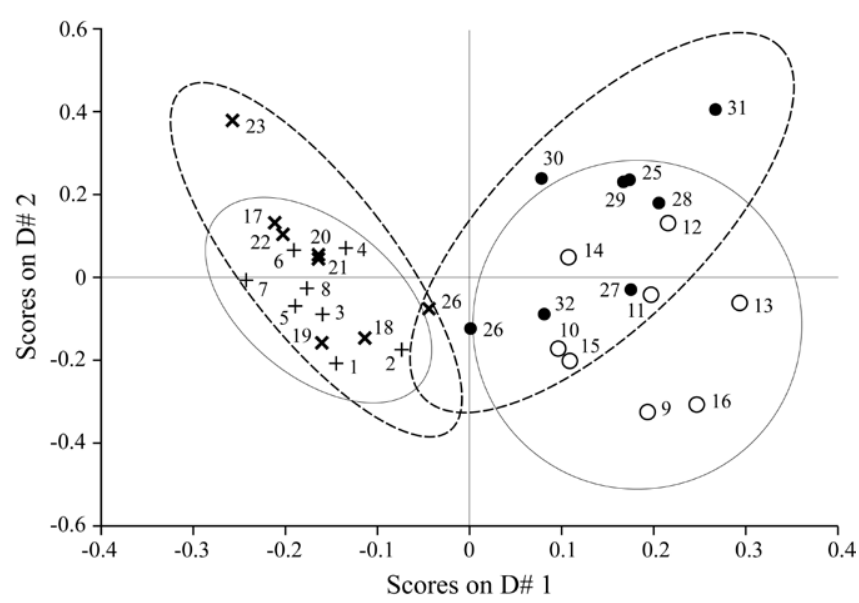

Figure 2. PCDA, Difference between grey and white matter (brain) of a Control (Co) and a Type-2 diabetes group (T2DM) in lipid composition. $\mathrm{G}=$ grey matter cortex, $\mathrm{W}=$ white matter cortex. On the left part of the figure grey matter is located, on the right part is white matter located. No significant difference between Co and T2DM group in lipid composition (109 lipid compounds).
A

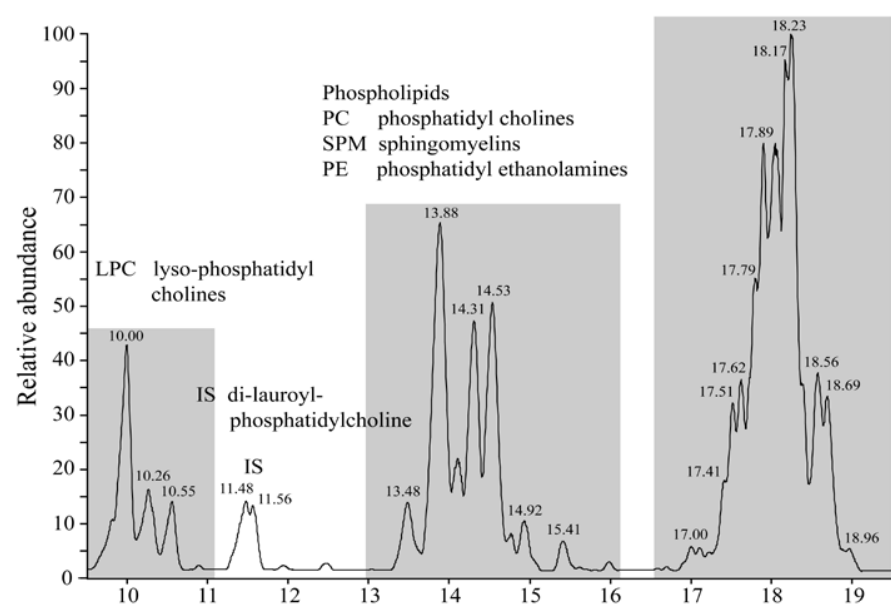

B

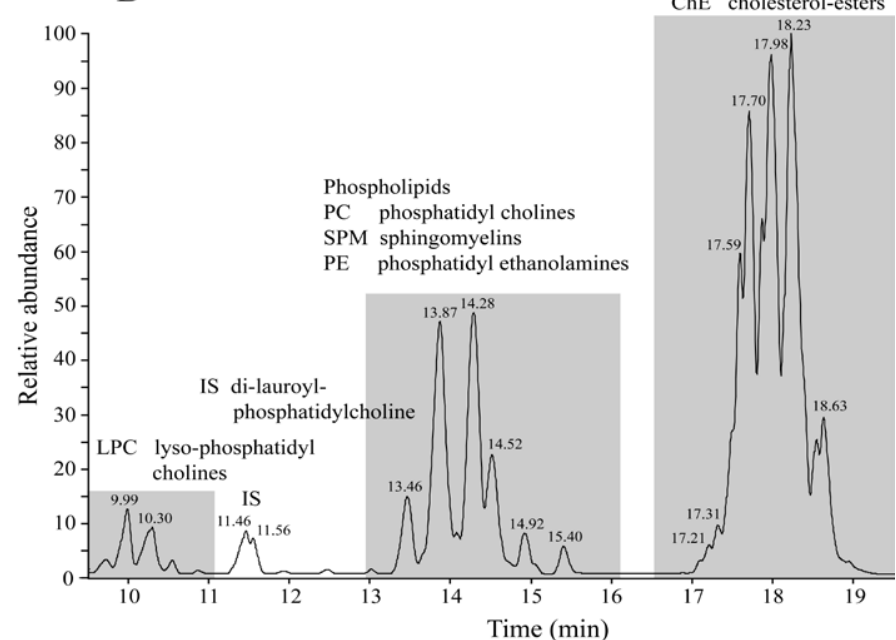

Figure 3. Using reversed phase liquid chromatography coupled to mass-spectrometry (LCMS) a chromatogram was obtained of blood plasma of a Co-patient no.1 (Figure 3A) and a type-2 diabetes (T2DM) patient (Figure 3B).

\section{Statistics}

For all measured parameters the mean value of the control postmortem human group was compared to the mean value of the postmortem T2DM human group. Statistics were performed via SPSS using one-way ANOVA for differences between control and T2DM groups. $\mathrm{P} \leq 0.05$ was considered as statistically significant. Normality of the data and homogeneity of variances were checked by Kolmogorov-Smirnov and $\mathrm{F}_{\text {max }}$ tests, respectively [34].

Principal Component Analysis (PCA) was carried out on the parameters of lipid metabolism measured via reversed phase liquid chromatography coupled to mass spectrometry. This type of analysis allows one to simultaneously examine the relative state of individuals according to three or more variables. We used Principal Component Analysis (PCA) statistical methods, which are specially developed, for application in biomedical research $[35,36]$, using TNO IMPRESS, EQUEST and WINLIN software.

Principal component analysis (PCA) is a classic statistical technique used to reduce multidimensional data sets to lower dimensions for analysis [37]. The applications include exploratory data analysis and 
Ginneken V (2017) Characterization of the lipid profile post mortem for Type-2 diabetes in human brain and plasma of the elderly with LCMS-techniques: a descriptive approach of diabetic encephalopathy

data for generating predictive models. PCA involves the computation of the eigenvalue decomposition or singular value decomposition of a data set, usually after mean centering the data for each attribute. The results of a PCA are usually discussed in terms of scores and loadings. The score and loading vectors give a concise and simplified description of the variance present in the dataset [38]. A principal component is a linear combination of the original variables (in this case: lipid concentrations) and the magnitude of its eigenvalue is a measure of the explained variance. Typically only a few principal components are required to explain $>90 \%$ of the total variance in the data. In other words PCA is a dimension reduction method, e.g. from $>100$ lipid attributes in the data to only a 4 principal components, which simplifies data visualization.

Because no differences were observed between the control and T2DM groups for both grey and white matter, a Principal Component Discriminant Analysis (PCDA) was performed. This is a supervised method forcing group separation based on the principle that PCDA is prone to overfitting (false positive models). PCDA is a powerful tool to identify and maximize differences between pre-defined groups in data sets with a large number of variables [39].

In lipidomics or proteomics the number of objects/subjects is often small and therefore a statistical method often used is classification: the assignment of subjects to discrete categories [38]. In our case healthy or Diabetic 2 (T2DM).

\section{Results}

With regard to patient selection from the "Netherlands Brain Bank", we aimed to obtain a representative sample of post mortem patients with T2DM which were comparable with the Co-group for sex (all male), age, Braak-stage [27,40], brain weight, ApoE genotype, and cause of death. Our groups were comparable for most criteria. The causes of death varied and were characteristic to elderly people (and not related to T2DM, Table 1). All patients were in Braak-stages varying between $0-2$ with exception of patient $\mathrm{Co}-7$ which was at stage 3 (Table 1).

Autopsy was rapid $(8.9 \pm 6.4 \mathrm{~h}$ for the control group and $7.1 \pm 1.8$ $\mathrm{h}$ for the T2DM group) (Table 1). The $\mathrm{pH}$ of the liquor ( $\mathrm{pH}$-csf) was comparable between the control and T2DM groups (control: $6.52 \pm$ 0.38; T2DM: $6.37 \pm 0.22$; Table 1). The brain weight of both patient groups was also comparable (control: $1319 \pm 140 \mathrm{~g} v s$. T2DM: $1337 \pm$ $145 \mathrm{~g}$; Table 1).

Our initial hypothesis that T2DM patients had more mental disorders was confirmed by our patient material. All control patients were non-demented. In the T2DM group patients had Non-Hodgkin lymphoma, multiple sclerosis, vascular dementia, Parkinson's disease or Parkinson's disease with dementia. These are diseased or mental disorders not related to lipid metabolism of the brain [10].

Using reversed phase liquid chromatography coupled to massspectrometry (LC-MS) a chromatogram was obtained of the brainhomogenate of a Co-patient no.1 (Figure 1A). Clearly visible are three groups of chemical compounds: A). 9-11 minutes retention time lyso-phosphatidylcholines (LPC) with at 11.5 minutes the Internal Standard di-lauroyl-phoshatidylcholine ; B). 13-16 minutes: Plasmalogens, Phosphatidylcholines (PC), Sphingomyelins (SPM) and phosphatidylethanolamines (PE); C). 17-19 minutes Triacylglycerols (TG) and Cholesteryl-esters (ChE). The chromatogram of a T2DM patient no.1 shows a similar pattern (Figure 1B).

In Figure 2 the results of a PCDA analysis presented indicating the difference between grey and white matter (brain) of a Control (Co) and a Type-2 diabetes group (T2DM) in lipid composition. On the left part of the figure grey matter is located, white matter is on the right part. From Table 2 we can conclude there are no significant difference between summarized relative concentrations of the different lipid compounds in human brain homogenate (white $v s$. grey) of two patients groups: one Control-group $(\mathrm{N}=8)$ and one Diabetes-2 group $(\mathrm{N}=8)$.

In Table 4, hormones, enzymes and substrates in blood plasma of eight Control subjects and eight Diabetes- 2 subjects are given.

Alanine aminotransferase (ALT), aspartate aminotransferase (AST), triacylglycerols, free fatty acids (NEFA), cholesterol, (HDL)cholesterol, were predictors for hypertriglyceridemia in liver whereas insulin, glucose, fructosamine were predictors for hyperglycemia in blood plasma.

Table 2. Summarized relative concentrations determined with LC-MS techniques of the different lipid compounds in human brain homogenate (white $v s$. grey) of two patients groups: one Control-group $(\mathrm{N}=8)$ and one Diabetes-2 group $(\mathrm{N}=8)$.

\begin{tabular}{|c|c|c|c|c|}
\hline Compound & $\begin{array}{c}\text { Control-white brain } \\
\text { Mean } \pm \text { SD }(n=8)\end{array}$ & $\begin{array}{l}\text { Diabetes-2-white brain } \\
\text { Mean } \pm \text { SD }(n=8)\end{array}$ & $\begin{array}{c}\Delta \mathrm{T} 2 \mathrm{DM} / \mathrm{Co} \\
\text { (in \%) }\end{array}$ & P-value \\
\hline$\sum-\mathbf{L P C}$ & $0.4118 \pm 0.1022$ & $0.3377 \pm 0.0868$ & $82.01 \%$ & $P \leq 0.1413$ \\
\hline$\sum$-SPM & $9.6031 \pm 1.4745$ & $8.9776 \pm 2.5746$ & $93.49 \%$ & $\mathrm{P} \leq 0.5629$ \\
\hline$\sum$-DG & $0.4568 \pm 0.1472$ & $0.4404 \pm 0.21419$ & $96.41 \%$ & $\mathrm{P} \leq 0.8612$ \\
\hline$\sum-\mathrm{PC}$ & $25.773 \pm 1.355$ & $24.568 \pm 0.906$ & $95.32 \%$ & $\mathrm{P} \leq 0.058$ \\
\hline$\sum-\mathbf{P E}$ & $1.6798 \pm 0.1719$ & $1.6915 \pm 0.3036$ & $100.70 \%$ & $\mathrm{P} \leq 0.926$ \\
\hline$\sum$-PE-plasmalogens & $6.5867 \pm 0.5215$ & $6.5586 \pm 1.7045$ & $99.57 \%$ & $\mathrm{P} \leq 0.9656$ \\
\hline$\sum$-ChE & $0.0690 \pm 0.0053$ & $0.0779 \pm 0.013$ & $112.89 \%$ & $\mathrm{P} \leq 0.097$ \\
\hline$\sum$-Total white & $44.580 \pm 1.871$ & $42.652 \pm 5.368$ & $95.68 \%$ & $P \leq 0.3632$ \\
\hline Compound & $\begin{array}{l}\text { Control-grey brain } \\
\text { Mean } \pm \text { SD }(n=8)\end{array}$ & $\begin{array}{l}\text { Diabetes-2-grey brain } \\
\text { Mean } \pm \text { SD }(n=8)\end{array}$ & $\begin{array}{c}\Delta \mathrm{T} 2 \mathrm{DM} / \mathrm{Co} \\
\text { (in \%) }\end{array}$ & P-value \\
\hline$\sum$-LPC & $0.2502 \pm 0.0489$ & $0.2221 \pm 0.0434$ & $88.78 \%$ & $\mathrm{P} \leq 0.2449$ \\
\hline$\sum$-SPM & $3.1015 \pm 0.6571$ & $3.2462 \pm 0.4956$ & $104.67 \%$ & $P \leq 0.6273$ \\
\hline$\sum$-DG & $0.0739 \pm 0.02373$ & $0.0775 \pm 0.0376$ & $104.94 \%$ & $\mathrm{P} \leq 0.8204$ \\
\hline$\sum-\mathrm{PC}$ & $23.385 \pm 2.126$ & $23.393 \pm 0.971$ & $100.03 \%$ & $\mathrm{P} \leq 0.9925$ \\
\hline$\sum-\mathbf{P E}$ & $1.028 \pm 0.1018$ & $1.018 \pm 0.0839$ & $98.98 \%$ & $\mathrm{P} \leq 0.8254$ \\
\hline$\sum$-PE-plasmalogens & $1.902 \pm 1.0552$ & $1.786 \pm 1.1403$ & $93.88 \%$ & $\mathrm{P} \leq 0.8353$ \\
\hline$\sum$-ChE & $0.0631 \pm 0.0053$ & $0.0685 \pm 0.0097$ & $108.45 \%$ & $\mathrm{P} \leq 0.1993$ \\
\hline$\sum$-Total grey & $29.804 \pm 3.730$ & $29.811 \pm 2.414$ & $113.56 \%$ & $P \leq 0.9965$ \\
\hline$\sum$ (white + grey) & $74.384 \pm 5.167$ & $72.463 \pm 6.294$ & $97.42 \%$ & $P \leq \mathbf{0 . 5 1 5 7}$ \\
\hline
\end{tabular}


Ginneken V (2017) Characterization of the lipid profile post mortem for Type-2 diabetes in human brain and plasma of the elderly with LCMS-techniques: a descriptive approach of diabetic encephalopathy

Table 3. Ratio of 16:0 to 18:0 fatty acids of brain homogenate (grey and white) of a Control Human patient-group ( $\mathrm{N}=8$ ) vs. a Type-2 diabetes Human patient-group (N=8). Data measured with LC-MS techniques and given (mean \pm SD) in Annex 1 for Lysophosphatidylcholines (LPC), Sphingomyelines (SPM) and Cholesterylesters (ChE).

\begin{tabular}{|c|c|c|c|c|}
\hline Compound & $\begin{array}{c}\text { Control-Grey } \\
\text { Mean } \pm \text { SD }(n=8)\end{array}$ & $\begin{array}{c}\text { Diabetes-2 Grey } \\
\text { Mean } \pm \text { SD }(n=8)\end{array}$ & $\begin{array}{l}\Delta \mathrm{Co} / \mathrm{T} 2 \mathrm{DM} \\
\text { Grey (in \%) }\end{array}$ & P-value \\
\hline 16:0 LPC & $0.13072 \pm 0.02826$ & $0.11386 \pm 0.02668$ & $87.10 \%$ & $\mathrm{P} \leq 0.240$ \\
\hline 18:0 LPC & $0.07993 \pm 0.01198$ & $0.07559 \pm 0.01053$ & $94.57 \%$ & $\mathrm{P} \leq 0.454$ \\
\hline 16:0 LPC/18:0 LPC & $162.412 \pm 16.541$ & $149.057 \pm 16.203$ & $91.78 \%$ & $\mathrm{P} \leq 0.125$ \\
\hline 16:0 SPM & $0.13134 \pm 0.02434$ & $0.15123 \pm 0.01845$ & $115.14 \%$ & $\mathrm{P} \leq 0.088$ \\
\hline 18:0 SPM & $1.14428 \pm 0.15877$ & $1.27275 \pm 0.09557$ & $111.23 \%$ & $\mathrm{P} \leq 0.075$ \\
\hline 16:0 SPM/18:0 SPM & $11.473 \pm 1.342$ & $11.901 \pm 1.389$ & $103.73 \%$ & $\mathrm{P} \leq 0.541$ \\
\hline 16:0 ChE & $0.00328 \pm 0.00027$ & $0.00395 \pm 0.00058$ & $120.33 \%$ & $\mathbf{P} \leq \mathbf{0 . 0 1 4} * \uparrow$ \\
\hline 18:0 ChE & $0.012136 \pm 0.00729$ & $0.011913 \pm 0.00150$ & $98.16 \%$ & $\mathrm{P} \leq 0.713$ \\
\hline 16:0 ChE/18:0 ChE & $27.126 \pm 2.834$ & $33.343 \pm 4.316$ & $122.92 \%$ & $\mathbf{P} \leq \mathbf{0 . 0 0 5 2} * * \uparrow$ \\
\hline$\Sigma 16: 0(\mathrm{LPC}+\mathrm{SPM}+\mathrm{ChE})$ & $0.26534 \pm 0.04253$ & $0.26903 \pm 0.03023$ & $101.39 \%$ & $\mathrm{P} \leq 0.845$ \\
\hline$\Sigma 18: 0(\mathrm{LPC}+\mathrm{SPM}+\mathrm{ChE})$ & $1.23635 \pm 0.15973$ & $1.36025 \pm 0.09132$ & $110.02 \%$ & $\mathrm{P} \leq 0.083$ \\
\hline$\Sigma(\operatorname{sum} 16: 0) / \Sigma(\operatorname{sum} 18: 0)$ & $21.6238 \pm 3.33633$ & $19.8470 \pm 2.53670$ & $91.78 \%$ & $\mathrm{P} \leq 0.252$ \\
\hline Compound & $\begin{array}{c}\text { Control-White } \\
\text { Mean } \pm \text { SD }(n=8)\end{array}$ & $\begin{array}{l}\text { Diabetes-2 White } \\
\text { Mean } \pm \text { SD }(n=8)\end{array}$ & $\begin{array}{c}\Delta \text { Co/T2DM } \\
\text { White (in \%) }\end{array}$ & P-value \\
\hline 16:0 LPC & $0.20295 \pm 0.04947$ & $0.16393 \pm 0.03655$ & $80.77 \%$ & $\mathrm{P} \leq 0.096$ \\
\hline 18:0 LPC & $0.09714 \pm 0.02322$ & $0.08956 \pm 0.01967$ & $92.20 \%$ & $\mathrm{P} \leq 0.493$ \\
\hline 16:0 LPC/18:0 LPC & $209.750 \pm 22.111$ & $183.288 \pm 17.764$ & $87.77 \%$ & $\mathbf{P} \leq \mathbf{0 . 0 2 0} * \downarrow$ \\
\hline 16:0 SPM & $0.51162 \pm 0.15007$ & $0.47324 \pm 0.14329$ & $92.50 \%$ & $\mathrm{P} \leq 0.609$ \\
\hline 18:0 SPM & $2.20663 \pm 0.30216$ & $2.19495 \pm 0.44360$ & $99.47 \%$ & $\mathrm{P} \leq 0.952$ \\
\hline 16:0 SPM/18:0 SPM & $22.922 \pm 4.536$ & $21.172 \pm 2.761$ & $92.37 \%$ & $\mathrm{P} \leq 0.370$ \\
\hline 16:0 ChE & $0.00340 \pm 0.000483$ & $0.00416 \pm 0.000612$ & $122.11 \%$ & $\mathbf{P} \leq \mathbf{0 . 0 1 6 9 * * \uparrow}$ \\
\hline 18:0 ChE & $0.01181 \pm 0.002248$ & $0.01386 \pm 0.00206$ & $117.36 \%$ & $\mathrm{P} \leq 0.078$ \\
\hline 16:0 ChE/18:0 ChE & $30.0618 \pm 8.1593$ & $30.3588 \pm 5.0503$ & $100.99 \%$ & $\mathrm{P} \leq 0.932$ \\
\hline$\Sigma 16: 0(\mathrm{LPC}+\mathrm{SPM}+\mathrm{ChE})$ & $0.71798 \pm 0.16172$ & $0.64133 \pm 0.16991$ & $89.32 \%$ & $\mathrm{P} \leq 0.371$ \\
\hline$\Sigma 18: 0(\mathrm{LPC}+\mathrm{SPM}+\mathrm{ChE})$ & $2.31557 \pm 0.30759$ & $2.29837 \pm 0.45653$ & $99.26 \%$ & $\mathrm{P} \leq 0.931$ \\
\hline$\Sigma(\operatorname{sum} 16: 0) / \Sigma($ sum $18: 0)$ & $30.848 \pm 4.380$ & $27.557 \pm 2.516$ & $89.33 \%$ & $\mathrm{P} \leq 0.092$ \\
\hline
\end{tabular}

Table 4. Measured parameters in eight Control subjects and eight Diabetes-2 subjects. Hormones, enzymes and substrates in blood plasma, Material derived from "the Netherlands Brain bank".

\begin{tabular}{|c|c|c|c|c|c|c|c|c|c|c|c|}
\hline No. & Autopsy & $\begin{array}{r}\text { Insulin } \\
(\mathrm{mU} / \mathrm{l})\end{array}$ & $\begin{array}{l}\text { Glucose } \\
(\mathrm{mmol} / \mathrm{l})\end{array}$ & $\begin{array}{l}\text { Fructo- } \\
\text { samine } \\
(\mu \mathrm{mol} / \mathrm{l})\end{array}$ & $\begin{array}{l}\text { Leptin } \\
\text { Plasma } \\
\text { (ng/ml) }\end{array}$ & $\begin{array}{c}\text { AST } \\
\text { (GOT) } \\
(\mathrm{U} / \mathrm{L})\end{array}$ & $\begin{array}{c}\text { ALT } \\
\text { (GPT) } \\
(\mathbf{U} / \mathbf{L})\end{array}$ & $\begin{array}{l}\text { HDL-Choles-terol } \\
\text { (mmol/l) }\end{array}$ & $\begin{array}{l}\text { Triacyl- } \\
\text { Glycerols } \\
(\mathrm{mmol} / \mathrm{l})\end{array}$ & $\begin{array}{l}\text { HDLC } \\
(\mu \mathrm{g} / \mathrm{ml})\end{array}$ & $\begin{array}{c}\text { NEFA } \\
(\text { FFA) } \\
(\mathrm{mmol} / \mathrm{l})\end{array}$ \\
\hline Co-1 & $00 / 097$ & 29 & 19 & 271.5 & 3.9 & h. & 2622.5 & 2.62 & 2.79 & 0.59 & 0.70 \\
\hline Co-2 & $01 / 054$ & 7 & 0.11 & 177.0 & 1.4 & 139.7 & 26.9 & 1.55 & 2.64 & 0.09 & 0.63 \\
\hline Co-3 & $01 / 055$ & 15 & 15.6 & 305.4 & 13.7 & 151.1 & 39.8 & 1.88 & 2.73 & 0.74 & 0.15 \\
\hline Co-4 & $01 / 115$ & 6 & 1.5 & 214.8 & 1.2 & 116.4 & 43.7 & 4.75 & 2.48 & 0.79 & 0.43 \\
\hline Co-5 & 03/009 & 5 & 21.5 & 235.0 & 4.4 & 417.3 & 410.3 & 4.68 & 3.54 & 0.89 & 0.30 \\
\hline Co-6 & $06 / 117$ & 5 & 2.5 & 151.9 & 27.6 & h. & 2734.0 & 0.74 & 3.14 & 0.20 & 0.58 \\
\hline $\mathrm{Co}-7$ & $98 / 326$ & 15 & n.s. & n.s. & 1.6 & n.s. & n.s. & n.s. & n.s. & n.s. & n.s. \\
\hline Co-8 & $00 / 142$ & $<4$ & 7.0 & 251.4 & 6.3 & 884.4 & 721.3 & 4.05 & 2.92 & 0.55 & 1.8 \\
\hline Mean \pm SD & & $10.75 \pm 8.60$ & $9.6 \pm 8.9$ & $229.6 \pm 53.3$ & $7.51 \pm 9.09$ & $341.8 \pm 327.2$ & $942.6 \pm 1212.8$ & $2.90 \pm 1.60$ & $2.90 \pm 0.35$ & $0.55 \pm 0.30$ & $0.66 \pm 0.54$ \\
\hline DM-1 & $01 / 194$ & $<4$ & 1.7 & 342.6 & 1.7 & 351.8 & 42.8 & 3.26 & 1.98 & 0.85 & 0.97 \\
\hline T2DM & 02/081 & $<4$ & 0.9 & 257.6 & 1.7 & h. & h. & 2.13 & 4.26 & 0.08 & 1.2 \\
\hline DM-3 & $02 / 258$ & 43 & 9.0 & 199.7 & 23.3 & 103.0 & 48.0 & 3.67 & 2.75 & 0.53 & 0.18 \\
\hline DM-4 & $04 / 024$ & 26 & 0.11 & 287.6 & 3.8 & h. & h. & h. & h. & 0.85 & 0.59 \\
\hline DM-5 & $04 / 233$ & $<4$ & 5.9 & 310.7 & 4.6 & h. & h. & 2.88 & 3.83 & 0.72 & 0.62 \\
\hline DM-6 & $05 / 298$ & 6 & 27.6 & 366.3 & 6.5 & 42.1 & 12.4 & 4.79 & 2.34 & 0.86 & 0.28 \\
\hline DM-7 & $98 / 280$ & 345 & 11.4 & 255.7 & 57.4 & 6510.4 & 2422.3 & 2.08 & 1.43 & 0.64 & 0.57 \\
\hline DM-8 & $00 / 256$ & $<4$ & 6.1 & 311.5 & 25.4 & 1448.9 & 1114.8 & 4.72 & 4.74 & 0.50 & 0.69 \\
\hline Mean \pm SD & & $\begin{array}{l}54.50 \pm \\
118.25\end{array}$ & $7.8 \pm 8.9$ & $291.4 \pm 53.2$ & $\begin{array}{c}15.55 \pm \\
19.39\end{array}$ & $\begin{array}{c}1691.2 \pm \\
2753.1\end{array}$ & $728.1 \pm 1056.4$ & $3.36 \pm 1.11$ & $3.05 \pm 1.24$ & $0.63 \pm 0.26$ & $0.64 \pm 0.33$ \\
\hline T-test & & $P \leq \mathbf{0 . 3 3}$ & $P \leq 0.71$ & $\mathrm{P} \leq 0.04 *$ & $P \leq 0.31$ & $P \leq 0.31$ & $P \leq 0.76$ & $P \leq 0.54$ & $P \leq 0.76$ & $P \leq 0.60$ & $P \leq 0.94$ \\
\hline
\end{tabular}

Abbreviation: AST: Aspartate aminotransferase; ALT: Alanine aminotransferase;

HDLC=High-Density-Lipoprotein Cholesterol; NEFA (FFA).

n.s.: no sample; h.: interference by in vitro hemolysis; *: denotes significant difference between Control and Diabetes-2 group $\mathrm{P} \leq 0.05$.

Both control and T2DM group had three characteristics for the metabolic syndrome, that is, triacylglycerols $>1.7 \mathrm{mmol} / \mathrm{l}$; HDL cholesterol $<0.9$ and fasting plasma glucose $>6.1 \mathrm{mmol} / \mathrm{l}(28)$. In our study the triacylglycerols, HDL cholesterol and glucose were $2.89 \pm$
$0.35 \mathrm{mmol} / \mathrm{l}, 0.55 \pm 0.30$ and $9.6 \pm 8.93 \mathrm{mmol} / \mathrm{l}$, respectively, for the control group and $3.05 \pm 1.24 \mathrm{mmol} / \mathrm{l}, 0.63 \pm 0.26$ and $7.84 \pm 8.92$ $\mathrm{mmol} / \mathrm{l}$, respectively, for the T2DM group (Table 4). 
Ginneken V (2017) Characterization of the lipid profile post mortem for Type-2 diabetes in human brain and plasma of the elderly with LCMS-techniques: a descriptive approach of diabetic encephalopathy

Of all selected blood plasma predictors for diabetes 2 only fructosamine was significantly $(\mathrm{P} \leq 0.04)$ increased in the $T 2 \mathrm{DM}$ group (Table 4). This is a reflection of the glycated plasma proteins, the most important of which is albumin (27). Because the half-life albumin is 19 days, fructosamine gives an estimation of average glycemic control over the previous 2-3 weeks.

Using reversed phase liquid chromatography coupled to massspectrometry (LC-MS) a chromatogram was obtained of the bloodplasma of a Co-patient no.1 (Figure 3A). Clearly visible are three groups of chemical compounds: A). 9-11 minutes retention time lysophosphatidylcholines (LPC) with at 11.5 minutes the Internal Standard di-lauroyl-phoshatidylcholine; B). 13-16 minutes: Phosphatidylcholines (PC), Sphingomyelins (SPM) and phosphatidylethanolamines (PE); C). 17-19 minutes Triacylglycerols (TG) and Cholesteryl-esters (ChE). The chromatogram of a T2DM patient no.1 shows a similar pattern (Figure 3B).

In Figure 4 the results of the PCA analysis of the plasma samples are presented. No significant difference between Co and T2DM group in lipid composition (109 lipid compounds) are found. Note that the T2DM patients are more scattered. This can possibly be explained by differences in the monoglycerides (see Figure 5 and Table 5).

In Figure 5 we see in a 3-Dimensional graph the differences for mainly Monoglycerides for a Human Control Group $(n=8$, mean depicted) and a Human Diabetes-2 (T2DM) group $(n=8$, mean depicted). From Table 5 we can see that for three Monoglycerides the values are significantly higher in the T2DM group. For 18:2 MG (P 0.048, increase with 193.4\%); for 20:3 MG ( $\mathrm{P} \leq 0.048$, increase with $270.0 \%)$ and for $24: 3 \mathrm{MG}(\mathrm{P} \leq 0.036$, increase with $222.5 \%)$.

\section{Discussion}

Numerous studies have reported lower levels of n-3 and n-6 PUFAs in membrane phospholipids of people suffering depression and schizophrenia. These deficiencies in PUFAs have been primarily observed in erythrocyte membranes [41], adipose tissue of depressed subjects [42] as well as phospholipids of post mortem brain samples of schizophrenics [1].

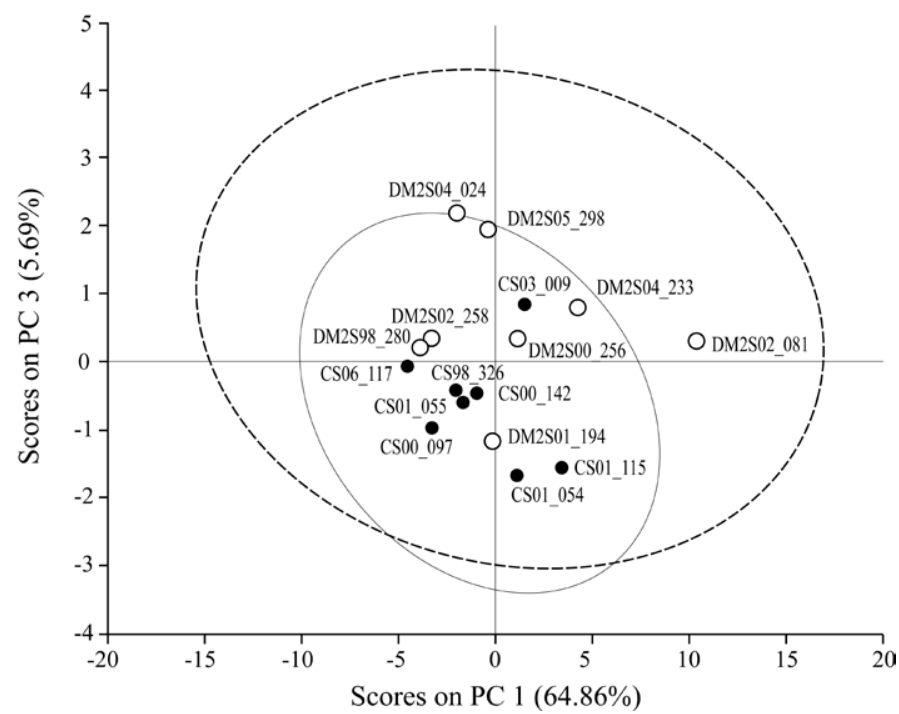

Figure 4. PCA: Difference in lipid composition of Control (Co, N=8) and Type-2 diabetes group ( $\mathrm{T} 2 \mathrm{DM}, \mathrm{N}=8$ ) in lipid composition of blood plasma. No significant difference between Co and T2DM group in lipid composition (109 lipid compounds). Note that the T2DM patients are more scattered.

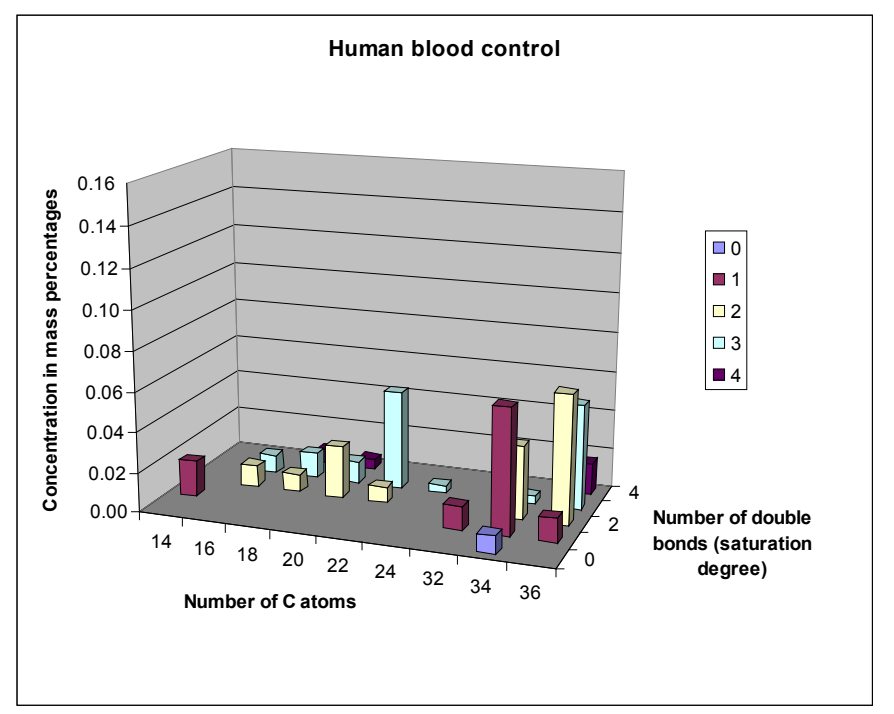

Human blood diabetis-2

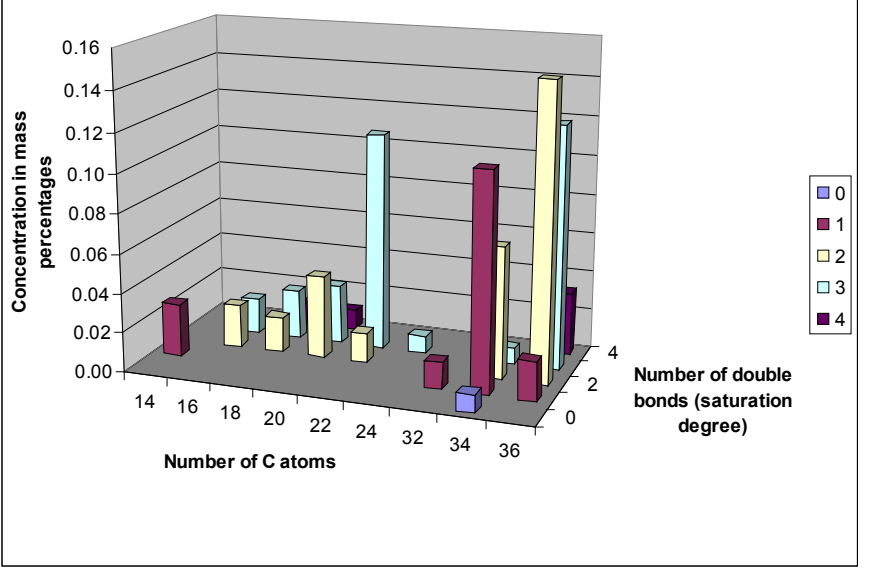

Figure 5. Differences in Monoglycerides between plasma of a Control and a Diabetes-2 (T2DM) group (mean value depicted).

To our awareness no extensive studies have been performed studying "diabetic encephalopathy" in relation to a brain aberrant lipid metabolism using cortex material from a brain bank in combination with LCMS techniques [24]. Some researchers concluded that further studies are required to explore the significance of mental disorders and establish if lipid levels could serve as markers for diagnostic and therapeutic purposes [43]. Therefore we performed this study using LCMS techniques in combination with brain (cortex) and blood material of male post mortem subjects (Control; $n=8 ; 73.5 \pm$ 10.5 years; Diabetes $-2(\mathrm{~T} 2 \mathrm{DM}) ; \mathrm{n}=8 ; 77.3 \pm 7.2$ years, Table 1$)$ from the 'Netherlands Brain Bank'. We quantified 109 lipid compounds, including cholesterylesters (ChE), lysophosphatidyl-cholines (LPC), phosphatidyl-choline (PC), sphingomyelin (SPM), triacylglycerols (TG), diacylglycerols (DG) and plasmalogens (PG). In general, for the lipid compounds in brain tissue no significant differences were observed between the Control and T2DM group for white as well as grey matter.

The only lipid fraction with significant differences in brain lipid composition between the Control and Type-2 diabetes group were 
Ginneken V (2017) Characterization of the lipid profile post mortem for Type-2 diabetes in human brain and plasma of the elderly with LCMS-techniques: a descriptive approach of diabetic encephalopathy

Table 5. Significant differences for Monoglycerides between a Human Control group $(n=8)$ and a Diabetes-2 (T2DM) group $(n=8)$.

\begin{tabular}{|c|c|c|c|c|}
\hline & Control & Diabetes & & Change in \\
\hline Compound & (Mean \pm SD) & (Mean \pm SD) & P-value & $\mathbf{( \% )}$ \\
\hline $\mathbf{1 4 : 1 - M G ~}$ & $0.018 \pm 0.007$ & $0.027 \pm 0.017$ & 0.202 & 148.69 \\
\hline $\mathbf{1 6 : 2 - M G}$ & $0.011 \pm 0.006$ & $0.022 \pm 0.017$ & 0.106 & 199.58 \\
\hline $\mathbf{1 6 : 3 - M G}$ & $0.009 \pm 0.007$ & $0.018 \pm 0.019$ & 0.217 & 197.00 \\
\hline $\mathbf{1 8 : 2 - M G}$ & $0.009 \pm 0.004$ & $0.018 \pm 0.011$ & $\mathbf{0 . 0 4 8} * \uparrow$ & $\mathbf{1 9 3 . 3 4}$ \\
\hline $\mathbf{1 8 : 3 - M G}$ & $0.013 \pm 0.011$ & $0.025 \pm 0.022$ & 0.195 & 191.90 \\
\hline $\mathbf{1 8 : 4 - M G}$ & $0.007 \pm 0.007$ & $0.011 \pm 0.014$ & 0.433 & 169.36 \\
\hline $\mathbf{2 0 : 2 - M G}$ & $0.026 \pm 0.014$ & $0.042 \pm 0.034$ & 0.234 & 161.34 \\
\hline $\mathbf{2 0 : 3 - M G}$ & $0.011 \pm 0.006$ & $0.030 \pm 0.024$ & $\mathbf{0 . 0 4 8} * \uparrow$ & $\mathbf{2 7 0 . 0 3}$ \\
\hline $\mathbf{2 0 : 4 - M G}$ & $0.005 \pm 0.004$ & $0.010 \pm 0.009$ & 0.148 & 217.61 \\
\hline $\mathbf{2 2 : 2 - M G}$ & $0.008 \pm 0.004$ & $0.015 \pm 0.007$ & 0.052 & 171.26 \\
\hline $\mathbf{2 2 : 3 - M G}$ & $0.050 \pm 0.016$ & $0.111 \pm 0.088$ & 0.073 & 223.60 \\
\hline $\mathbf{2 4 : 3 - M G}$ & $0.004 \pm 0.002$ & $0.009 \pm 0.006$ & $\mathbf{0 . 0 3 6} * *$ & $\mathbf{2 2 2 . 4 5}$ \\
\hline
\end{tabular}

the Monoglycerides (Figure 5 although the T2DM patients were more scattered for lipid composition (109 compounds) in blood plasma (Figure 4).

A review study [22] with healthy Control patients, in comparison with schizophrenic patients; observed major differences of phospholipids fatty acids of phospholipids in the cingulate cortex brain region. Schizophrenic patients had significant lower C16:0-FA in grey matter in comparison to control patients. For white matter there were no significant differences [1]. To investigate this for T2DM, we compared the lipid biochemical composition of the cortex between a control group and a T2DM patient group. Our data corroborate the observations of this study [1] that the fatty acid C16:0 may be important in mental disorders. In our study we observed that the saturation index of the ChE for 16:0 was significantly higher in white matter of T2DM patients in comparison to white matter of the control group $(\mathrm{P} \leq 0.05)$. So the C16:0 compound was significantly higher in comparison to the unsaturated 16:1 compound (Annex 1). Another positive result was the observed difference between grey and white matter of the brain (all over the groups) (Figure 2).

The mean brain weight of a (younger) Control group of male patients reported in literature was $1449 \pm 152 \mathrm{~g}(\mathrm{n}=87)$. But these patients were younger and had a mean age of 38.5 years [44]. So our patient groups, although older, were in the range of this study [44].

In a study [45] it was demonstrated in a murine animal model that T2DM can contribute to mild neurodegeneration resulting in a lower brain weight due to brain shrinking and global atrophy in the brain. These findings suggest that strategies to reduce obesity and prevent or control T2DM -which could modify the clinical course of mild cognitive impairment- are clearly warranted. In our T2DM patient group this phenomena was not observed.

Lipids play a key role in determining membrane fluidity, and changes in lipid and fatty acids composition have been reported to alter important cellular functions [1,22,23]. A decreased membrane polysaturation may act to decrease the activity of the major energyconsuming processes of the cell such as reducing the flux of ions and protons and subsequently the energy needed to maintain ionic homeostasis.

Membrane fatty acid composition influences insulin action via alteration of membrane proteins specifically associated with the action of insulin. Such mechanism would include modulation both of receptor affinities and translocation to the membrane of nutrient transporters [22].
In this study we measured also hormones like insulin and leptin in plasma and brain homogenate and we hoped to find different ratio's between Co and T2DM groups that could be indicative for a changed blood-brain barrier $[45,46]$.

In our study leptin and insulin were below the detection limit in cortex homogenate in Co as well as T2DM groups. So we could make no conclusions about an altered blood barrier in the brain. In contrast, by gadolinium Magnetic Resonance Imaging (MRI) it was demonstrated that the blood-brain barrier permeability increased in patients with T2DM [17].

Recent studies indicate that glycaemic control is implicated in the development of cognitive dysfunction. Insulin dysregulation and hyperglycaemia may play an important role in neurodegeneration [47]. Exaggerated postprandial glucose (PPG) excursions are associated with a derangement of both global, executive, and attention function. In addition, it was concluded by [47] that a tighter control of PPG may prevent cognitive decline in older diabetic individuals.

To date, its pathogenic mechanism are largely unclear. Cognitive impairments in patients with T2DM have been associated with vascular risk factors, such as hypertension and dyslipidemia, and with diabetesrelated factors, such as glycemic control, duration of the disease and treatment modality [48].

This is confirmed by our observation that fructosamine was significantly $(\mathrm{P} \leq 0.04)$ increased in the $\mathrm{T} 2 \mathrm{DM}$ group (Table 3 ). Fructosamine gives an estimation of average glycemic control over the previous 2-3 weeks [49]. Hyperglycemia may directly affect neuronal viability [36].

This is the first descriptive study in which we examined with LCMS techniques > 100 lipid compounds of T2DM versus Co in the brain cortex and blood plasma. We have to acknowledge that other brain area's like the hippocampus [50] are also very interesting to investigate but this material is very scarce for post-mortem Co and T2DM patients.

Via our descriptive approach we can conclude that for biochemical lipid composition for T2DM patients the brain is very stable and that mental disorders more have to be found in the neural functioning (conduction and/or transmission) resulting in slowing down brain functioning $(38,39)$ and glycaemic control than in the biochemical lipid composition.

Our major conclusion is that diabetes and its treatment are more associated with glycaemic control than structural disturbances (lipid composition) in the brain. So probably "Diabetic encephalopathy", is a term that encompasses functional impairment of cognition, cerebral cognition, cerebral signal conduction, neurotransmission and synaptic plasticity, and underlying structural pathology associated with type2diabetes. In order to make a complete picture in another manuscript the saturation degree [22] of white as well as grey matter of the presented material is presently under investigation.

\section{Conflict of interest}

\section{None}

\section{Acknowledgements}

Dr.M. Rademaker and Dr. M. Kooreman of the Netherlands Brain bank, Netherlands Institute for Neuroscience, Amsterdam, Netherlands are kindly acknowledged for help with the selection of the patient material. The protocol number of this project was 2007/516. 
Ginneken V (2017) Characterization of the lipid profile post mortem for Type-2 diabetes in human brain and plasma of the elderly with LCMS-techniques: a descriptive approach of diabetic encephalopathy

\section{References}

1. Yao JK, Leonard S, Reddy RD (2000) Membrane phospholipid abnormalities in postmortem brain from schizophrenic patients. Schizophrenia Res 42: 7-17. [Crossref]

2. Lutz W, Sanderson W, Scherbov S (2008) The coming acceleration of global population ageing. Nature 451: 716-719. [Crossref]

3. Rolfes SR, Pinna K, Whitney E (2009) Understanding normal and clinical Nutrition. Wadsworth, Cengage Learning, ISBN-13: 978-0-495-5564-6, 925 pp.

4. Stenholm S, Harris TB, Rantanen T, Visser M, Kritchevsky SB, et al. (2008) Sarcopenic obesity: definition, cause and consequences. Curr Opin Clin Nutr Metab Care 11: 693 700. [Crossref]

5. Stenholm S, Harris TB, Rantanen T, Visser M, Kritchevsky SB, et al. (2008) Sarcopenic obesity: definition, cause and consequences. Curr Opin Clin Nutr Metab Care 11: 693700. [Crossref]

6. Handschin C, Spiegelman BM (2008) The role of exercise and PGClalpha in inflammation and chronic disease. Nature 454: 463-469. [Crossref]

7. Rowley WR, Bezold C, Arikan Y, Byrne E2, Krohe S3 (2017) Diabetes 2030: Insights from Yesterday, Today, and Future Trends. Popul Health Manag 20: 6-12. [Crossref]

8. Boulton AJ, Vinik AI, Arezzo JC, Bril V, Feldman EL, et al. (2005) Diabetic neuropathies: a statement by the American Diabetes Association. Diabetes Care 28: 956-962. [Crossref]

9. Hanefeld M, Fischer S, Julius U, Schulze J, Schwanebeck U, et al. (1996) Risk factors for myocardial infarction and death in newly detected NIDDM: the Diabetes Intervention Study, 11-year follow-up. Diabetologia 39: 1577-1583. [Crossref]

10. Niskanen L, Turpeinen A, Penttila I, Uusitupa MI (1998) Hyperglycemia and compositional lipoprotein abnormalities as predictors of cardiovascular mortality in type 2 diabetes: a 15-year follow-up from the time of diagnosis. Diabetes Care 21: 1861-1869. [Crossref]

11. Biessels GJ, Luchsinger JA (2010) Diabetes and the Brain. Series: Contemporary Diabetes, 474 pp.; ISBN 978-1-60327-849-2, Springer Verlag.

12. Abbatecola AM, Rizzo MR, Barbieri M, Grella R, Arciello A, et al. (2006) Postprandial plasma glucose excursions and cognitive functioning in aged type 2 diabetics. Neurology 67: 235-240. [Crossref]

13. Mijnhout GS, Scheltens P, Diamant M, Biessels GJ, Wessels AM, et al. (2006) Diabetic encephalopathy: A concept in need of a definition. Diabetologia 49: 1447-1448. [Crossref]

14. van den Berg E, Kessels RP, Kappelle LJ, de Haan EH, Biessels GJ et al. (2006) Diabetic Encephalopathy Study Group: Type 2 diabetes, cognitive function and dementia: vascular and metabolic determinants. Drugs Today 42: 741-754. [Crossref]

15. Lustman PJ, Clouse RE (2005) Depression in diabetic patients: the relationship between mood and glycemic control. J Diabetes Complications 19: 113-122. [Crossref]

16. Egede LE, Nietert PJ, Zheng D (2005) Depression and all-cause and coronary heart disease mortality among adults with and without diabetes. Diabetes Care 28: 13391345. [Crossref]

17. Mezuk B, Eaton WW, Albrecht S, Golden SH (2008) Depression and type 2 diabetes over the lifespan: a meta-analysis. Diabetes Care 31: 2383-2390. [Crossref]

18. Starr JM, Wardlaw J, Ferguson K, MacLullich A, Deary IJ, Marshall I (2003) Increased blood-brain barrier permeability in type II diabetes demonstrated by gadolinium magnetic resonance imaging. J Neurol Neurosurg Psych 74: 70-76. [Crossref]

19. Veves A, Malik RA (2007) Diabetic Neuropathy, Second Edition, Humana Press, ISBN 978-1-58829-629-9, 187-205.

20. Le TK, Able SL, Lage MJ (2006) Resources use among patients with diabetes, diabetic neuropathy, or diabetes with depression. Cost Eff Resour Alloc 4:18. [Crossref]

21. Clore JN, Li J, Gill R, Gupta S, Spencer R, et al. (1998) Skeletal muscle phosphatidylcholine fatty acids and insulin sensitivity in normal humans. Am J Physiol 275: E665-670. [Crossref]

22. Borkman M, Storlien LH, Pan DA, Jenkins AB, Chisholm DJ, et al. (1993) The relation between Insulin sensitivity and the Fatty-Acid composition of skeletal-muscle Phospholipids. NEJM 328: 238-244. [Crossref]

23. Hulbert AJ, Turner N, Storlien LH, Else PL (2005) Dietary fats and membrane function: implications for metabolism and disease. Biol Rev Camb Philos Soc 80: 155-169. [Crossref]
24. Bourre JM, Dumont O, Piciotti M, Clément M, Chaudière J, et al. (1991) Essentiality of omega 3 fatty acids for brain structure and function. World Rev Nutr Diet 66: 103117. [Crossref]

25. Dimopoulos N, Piperi C, Salonicioti A, Psarra V, Mitsonis C, et al. (2007) Characterization of the lipid profile in dementia and depression in the elderly. $J$ Geriatr Psychiatry Neurol 20: 138-144. [Crossref]

26. Feldman EL, Stevens MJ, Greene DA (1999) Diabetic neuropathy. In: Diabetes in the New Millenium. (Turtle J.R.; Kaneko, T.; Osato, S. eds.) The Endocrinology and Diabetes Research Foundation of the University of Sydney, Sydney, pp. 387-402.

27. Manschot S (2006) Diabetic Encephalopathy: a cerebrovascular disorder? PhD-Thesis, Utrecht University, Netherlands, 141 pp. ISBN-10: 90-393-4204-0.

28. Braak H, Braak E, Bohl J (1993) Staging of Alzheimer-related cortical destruction. Eur Neurol 33: 403-408. [Crossref]

29. van Ginneken V, Verheij E, Poelmann R, Ramakers R, van Dijk KW, et al. (2007) Metabolomics (liver and blood profiling) in a mouse model in response to fasting: a study at hepatic steatosis. Biochim Biophysic Acta 1771: 1263-1270. [Crossref]

30. van Ginneken V, Verheij E, Hekman M, Feskens E, van der Greef J, et al. (2010) The comparison of lipid profiling in Mouse brain and liver after starvation and a fatty diet a Medical Systems Biology approach. Chapter 3 In: Biology of Starvation in Human and other organisms. Editor: Todd C. Merkin, ISBN: 978-1-61122-546-4, Nova Science Publishers, Inc. Pages 151-187.

31. van Ginneken V, de Vries E, Verheij E, van der Greef J (2016) Metabolomics in Hind limb and Heart Muscle of a Mouse Model after a High-fat Diet. Anat Physiol 6:214. doi:10.4172/2161-0940.1000214.

32. van Ginneken VJT, Booms R, Verheij E, de Vries E, van der Greef J (2016) The Relation between Non-adipose Muscle Fat and Hepatic Steatosis Studied with Localized 1H Magnetic Resonance Spectroscopy (1H MRS) and LCMS Techniques. Anat Physiol 6: 245 .

33. Ginneken V, Verheij E, de Vries E, van der Greef (2016) The discovery of two novel biomarkers in a high-fat diet C56bl6 Obese Model for Non-adipose tissue: a Comprehensive LCMS Study at Hind Limb, Heart, Carcass Muscle, Liver, Brain, Blood Plasma and Food Composition Following a Lipidomics LCMS-Based Approach. Cellular Mol Med Open access 2: 2:13.

34. Hsu FF, Turk J (2005) Electrospray, electrospray ionization with low-energy collisionally activated dissociation Tandem Mass Spectrometry of Complex Lipids: Structural Characterization and mechanisms of fragmentation. In: Modern methods for lipid analysis by Liquid Chromatography/Mass Spectrometry and related Techniques, W.C. Byrdwell, Editor, AOCS Press.

35. Field A (2005) Discovering Statistics Using SPSS, Sage Publications ltd, ISBN$0-7619-4451-6,779$ pages.

36. van der Greef J, Davidov E, Verheij ER, Vogels J, van der Heijden R, Adourian AS, Oresic M, Marple EW, Naylor S (2003) The role of metabolomics in Systems Biology. In: R.G. G.G. Harrigan (Ed), Metabolic Profiling: its Role in Bomarker Discovery and Gene Function Analysis. Vol. 170. Kluwer Academic Publisher, Boston/Dordrecht/ London.

37. van der Greef J, van der Heijden R, Verheij ER (2004) The Role of Mass Spectrometry in Systems Biology: Data Processing and Identification Strategies in Metabolomics. In: GBAE Ashcroft, JJ Monaghan (Ed): Advances in Mass Spectrometry, pp. 145-165. Vol. 16. Elsevier Science, Amsterdam.

38. Jackson JE (1991) A User's Guide to Principal Components. New York: Wiley.

39. Hendriks MMWB, Smit S, Akkermans WLMW, Reijmers TH, Eilers PHC, et al (2007) How to distinguish healthy from diseased? Classification strategy for mass spectrometry-based clinical proteomics. Proteomics 7: 3672-3680. [Crossref]

40. Hoogerbrugge R, Willig SJ, Kistenmaker PG (1983) Discriminant analysis by double stage principal component analysis. Anal Chem 55: 1710-1712.

41. Corder EH, Saunders AM, Strittmatter WJ, Schmechel DE, Gaskell PC, Small GW, Roses AD, Haines JL, Pericak-Vance MA (1993) Gene dose of apolipoprotein E type-4 allele and the risk of Alzheimer's disease in late onset families. Science 261: 921-923. [Crossref]

42. Peet M, Murphy B, Shay J, Horrobin D (1998) Depletion of omega-3 fatty acid levels in red blood cell membranes of depressive patients. Biol Psychiatry 43: 315-319. [Crossref]

43. Mamalakis G, Tornaritis M, Kafatos A (2002) Depression and adipose essential polyunsaturated fatty acids. Prostaglandins Leukot Essent Fatty Acids 67: 311-318. [Crossref] 
Ginneken V (2017) Characterization of the lipid profile post mortem for Type-2 diabetes in human brain and plasma of the elderly with LCMS-techniques: a descriptive approach of diabetic encephalopathy

44. Hernandez LM, Blazer DG (2006) Genes, Behavior, and the Social Environment: Moving Beyond the Nature/Nurture Debate Committee on Assessing Interactions Among Social, Behavioral, and Genetic Factors in Health, Editors; ISBN: 0-30966045-9: 384 pp.

45. Hamilton SJ, McMahon RF (2002) Sudden death and suicide: a comparison of brain weight. Br J Psychiatry 181: 72-75. [Crossref]

46. Moroz N, Tong M, Longato L, Xu H, de la Monte SM (2008) Limited Alzheimer-type neurodegeneration in experimental obesity and type 2 diabetes mellitus. J Alzheimers Dis 15: 29-44. [Crossref]

47. Banks WA (2006) The dam breaks: disruption of the blood-brain barrier in diabetes mellitus. Am J Physiol Heart Circ Physiol 291: H2595-2596. [Crossref]
48. Kumar R, Looi JC, Raphael B (2009) Type 2 diabetes mellitus, cognition and brain in aging: A brief review. Indian J Psychiatry 51 Suppl 1: S35-38. [Crossref]

49. Korf ES, White LR, Scheltens P, Launer LJ (2006) Brain aging in very old men with type 2 diabetes: the Honolulu-Asia Aging Study. Diabetes Care 29: 2268-2274. [Crossref]

50. Salway JG (2006) Medical Biochemistry at a glance; Blackwell Publishing LTD ISBN-13:978-4051-1322-9, 144

51. Magarainos AM, Mcewen BS (2000) Experimental diabetes in rats causes hippocampal dendritic and synaptic reorganization and increased glucocorticoid reactivity to stress. Proc Natl Acad Sci USA 97: 1,056-1,061. [Crossref]

Copyright: $@ 2017$ Ginneken V. This is an open-access article distributed under the terms of the Creative Commons Attribution License, which permits unrestricted use, distribution, and reproduction in any medium, provided the original author and source are credited. 